\title{
The Analysis of Network Expressions Under the Positive Energy Ecology of Real Society
}

\author{
Wang Sha, Xiao Jiugen \\ Research Center of Language and Language Life, Jiangxi Normal University, Nanchang, China \\ Email address: \\ 756987919@qq.com (Wang Sha),jxsdxjg666666@sina.com (Xiao Jiugen)

\section{To cite this article:} \\ Wang Sha, Xiao Jiugen. The Analysis of Network Expressions Under the Positive Energy Ecology of Real Society. Humanities and Social \\ Sciences. Vol. 8, No. 3, 2020, pp. 100-103. doi: 10.11648/j.hss.20200803.13
}

Received: April 29, 2020; Accepted: June 20, 2020; Published: June 29, 2020

\begin{abstract}
At the end of the 20th century, with the rapid development of modern science and technology, the world has entered an Internet era, and a new mainstream medium -- network language has emerged. In this Internet age, Chinese Internet language has gone through such a process: from extensive to standard and orderly, from transmitting negative energy to advocating positive energy, and from immature at the beginning to mature today. A review of the "top ten Internet expressions of the year" released by the China language resources monitoring and research center from 2015 to 2019 shows that most of these Internet buzzwords are closely related to social life, and the number of cyber languages that embody core socialist values has also increased significantly. For example, the "top 10 cyber languages" in 2019 reflects this feature. In terms of its annual network buzzwords, much of which comes from the social life and political events, positive energy is the main melody, it has showed people not only pay attention to own life, also pay attention to the social life, and the thought and behavior also gradually return to unity, made the network language toward the right direction of healthy and orderly development. Of course, cyber language has also brought some bad effects, but we should not give up eating for fear of choking, we should give correct guidance, because it is still in the process of constant development and change, so the country will always be on the road to its regulatory norms.
\end{abstract}

Keywords: Buzzwords, Positive Energy, Contemporaneity

\section{Introduction}

In the late 20th century, with the rapid development of modern technology, China also entered a new Internet era. In this era of the Internet, not only people's social life has changed dramatically, but also its communication language has also appeared unprecedented changes - the emergence of network language. Network language, at first, is just a way of chatting, buffoonery and making fun of the Internet, but over time it has become a special communication language. Such a new language has attracted the attention of many scholars. Scholars have studied it from scratch, from less to more, from one field to more than one field, such as sociology, communication, linguistics, translatology, education, psychology, ecology and other aspects of the multi-angle, comprehensive investigation, and a lot of research results. For example, Yao Zhihua divides the development history of China's network language into three stages, and analyzes it from the aspects of its language characteristics, spreading scope and netizens' attitude.[1] Yu Genyuan [2]、 Liu Haiyan [3] systematically expounded the classification, characteristics and causes of network language. Zhang Xuemei and Chen Changlai start from a single network buzzword to analyze the semantic evolution of its vocabulary and the reasons for its evolution. [4] Liu Kaihua combined network buzzwords with communication studies to analyze the emerging language phenomenon of network language in the context of social media and the underlying social motivations. [5] In her thesis, Chen Ning argues that we should have a correct understanding of the influence of network language on the development of Chinese language and culture, and asks people to make effective use of its positive factors to develop our Chinese language and literature. Tian Yongfang investigated the use and attitude of college students' network buzzwords, and believed that network buzzwords not only impact the purity of Chinese, but also enrich the campus network culture, and suggested that teachers should apply network buzzwords to classroom 
teaching to improve the interaction between teachers and students. [6] In recent years, ecology has become a hot topic in academic research, and it has become a trend for scholars to combine ecology and language, so the study of network buzzwords from the perspective of ecology emerges at the right moment. [7] The initial network language is mainly for entertainment, but has little connection with social reality and traditional values. Now the network language has become more and more powerful to convey a positive social energy, which can well reflect the core values of socialism. Based on the buzzwords released by the Internet information center, this paper discusses the phenomenon of network language under the positive energy ecology from the perspective of the positive energy of network language, which is seldom paid attention to and never discussed.

\section{Five Years of Internet Parlang at a Glance}

People in the society are divided into different speech societies because of their gender, age and social division of labor, each kind of community speech is the characteristic language branch or language variant - social dialect which is produced on the basis of the whole people's language. Social dialect is a kind of variation in language use among people of different ages, genders, occupations, educational levels, economic conditions, classes and social strata, [8] among which network language also belongs.

Network language is the discourse used by people when they use the Internet, including two meanings: one refers to the terms related to the Internet and its applications, such as "hard disk", "memory", "wireless lan", "computer desktop", "Internet", "wireless router" and so on; The second is the language people use to communicate and express through the Internet media, such as "fans" (supporters), "grey matter" (very), "3 grams of oil" (thank you), "CP" (lovers), "diving" (only read the post without giving opinions) and so on. Since the 21 st century, China's politics, economy, culture and other aspects of rapid development, network language has been produced, developed and spread at an unprecedented speed, many of which have gone out of the virtual network world into real life.

In 2019, China Internet Network Information Center (CNNIC) released The 44th China Statistical Report on Internet Development. By the end of June 2019, the number of Internet users in China had reached 854 million and the Internet penetration rate had reached $61.2 \%$, which has exceeded the average level of the world and Asia. [9] (page 15) The following is the annual "top ten network terms" from 2015 to 2019 released by the national language resources monitoring and research center. This is extracted from the national language resources monitoring corpus (part of network media) "mainly based on intelligent information processing technology, supplemented by manual fine-tuning in the later stage", which is highly authoritative. [10]
2019: Never forget why you started/ All roads lead to Rome, but safety comes first/ Green-eyed monster/ Feel so high/ This guy's a beast/ It's none of your business/ Hardcore/ 996 work schedule/ 1.4 Billion Flag Guards/ Minimalist Living: less is more

2018: Koi fish/ Argumentative person/ skr/ Buddha-like/ Soul gaze/ Officially announce/ Center position/ Cheesy pick-up lines/ Play a tri/ Burn my calories

2017: Beat a call/ Awkward chat/ Won't your conscience hurt?/ Surprise?/ Mantis Shrimp, get a move on/ My heart was pricked, Laotie/ Words fail me/ Pick on sb/ Can you freestyle?/ Oily

2016: Prehistoric power/ The ship of friendship/ Set a small goal/ The people who are kept in the dark/ Ge You lay/ Hard on the eyes/ It's all tricks/ Feel awful and want to cry/ Veteran netizen/ My brother, you're wonderful

2015: Important things are to be repeated for 3 times/ The world is so big, yet I owe it a visit/ Your urban folks are really born to mock/ Prop up the shares for the motherland/ He wastes his beautiful face by making a living by his talent/ Please leave me alone/ Scare baby to death/ My heart is almost collapsed at the moment/ My mum is my mother/ Focus on the aura

The above Internet buzzwords are all derived from real events in real life and are closely related to social life. It is a mirror of social life, from which we can see the real face of social life.

\section{Network Language to Convey Positive Energy as the Main Melody}

At the beginning of the Internet, the composition of netizens was mainly composed of teenagers. The network language is basically of the time to meet online chat and spontaneous creation, not according to the language specification requirements or other standards, only for the convenience of entertainment, leisure chat, so there is a lot of sex itself, often the sham as the genuine, pass information is in the majority of negative energy, such as dinosaurs, frog, amateurs, and so on. At that time, the Internet language was only related to the user, and the Internet was a place outside the law, where people said and did what other people did not know, and they were not responsible for what they had said or done. At that time, the source of network language is mainly entertainment programs, while the current network language is derived from social events or social phenomena. The number of such terms reflecting the core socialist values has increased significantly, such as the "top 10 network words" in 2019, which reflects this feature. The following is some specific analysis of the work.

" Never forget why you started ", the original intention is not to forget the original wish. Later, general secretary $\mathrm{Xi}$ Jinping in the 19th national congress of the communist party of China's report on the original intention and mission of the communist party of China, the term became widely circulated. Now, this phrase is always reminding people to 
find the original heart, remember the original heart, keep the original heart, to achieve their own goals and strive for the realization of the revitalization of the country, its positive meaning is increasingly prominent. The original meaning of this term only lies in personal ideals and beliefs, but the general secretary endowed it with a new ideological connotation and a new spirit of The Times, making it a code of conduct for communists and a general mobilization order that best represents the interests of the people, promotes social progress and realizes national rejuvenation.

"1.4 billion flag guards", a slogan from the Hong Kong incident. In the face of the rioters' insult to the national flag, CCTV news published the topic of " 1.4 billion flag bearers for the five-star red flag" on its microblog, and the message was forwarded by netizens. This network phrase is issued by CCTV, expressed the love of the motherland, protect the national flag of the sincere feelings, thus in the vast number of patriotic Internet users have a very strong resonance. This net expression that transmits positive energy is forwarded by netizen extensively subsequently, indicative netizen pays close attention to current social event and national event.

"Thousands of roads, the first safety (All roads lead to Rome, but safety comes first) ", this is from the movie Wandering Earth a line, and then many traffic police as a traffic safety propaganda language used. Netizens copied the sentence pattern to create "thousands of $\times \times$, the first $\times \times$," a number of words, this network language has been widely spread. For example, the background of "thousands of meetings, the first to do", "thousands of achievements, the first to value" and so on all come from social events, which also reflects the concern of netizens about social events.

The "996 work schedule ", which originally referred to working hours from $9 \mathrm{am}$ to $9 \mathrm{pm}$, six days a week, represented the culture of overtime prevalent in Chinese Internet companies. Alibaba group chairman of the board before said "996 work schedule" is revised to the merits of a stone up, this sentence has caused great repercussions on the Internet. This shows that people pay attention to and participate in social events. The fact shows that nowadays people are no longer the women who don't go out for a long time. They have already walked out of themselves, walked into the society and become the masters of the society.

"Hardcore" was originally a powerful rap music art style with a strong sense of rhythm, which was later extended as "things with certain difficulty and threshold of appreciation for the core audience". Now it is used to describe "very powerful", "very tough", such as "hardcore mother", "hardcore life" and "hardcore science fiction", and so on. It is associated with social phenomena, and has been popular and favored by the public. It reflects people's praise of a kind of power with positive energy, and also reflects people's enthusiasm for paying attention to social issues. [10]

On June 6, 2018, People's Daily online published an article calling for Internet buzzwords to release social values. [11] Ministries and commissions of the state also pay close attention to Internet language, advocate that Internet language should conform to the core socialist values, guide people to carry out communicative activities with positive and sunny words, and promote the harmonious development of society. According to the "top 10 Internet phrases of the year" from 2015 to 2019 , only "Never forget why you started " and "1.4 billion flag guards" among the 50 terms are from official language of national ministries and commissions, while most of the rest come from entertainment and other programs. However, after careful analysis, it is clear that the negative entertainment component of Internet language is greatly reduced, and the positive energy with positive meaning is gradually increasing. This has shown that people are not only concerned about themselves, but also about society, and people's thoughts and behaviors are gradually returning to unity. In other words, the value orientation of network language has shifted from virtual communication, network carnival to social care. [1] Different from the original Internet users' pursuit of unconventional Internet language, today's Internet users are pursuing the right to speak, which is not only an identifier to satisfy their identity, but also a barometer for the public to judge social issues. The progress of human society, the development of network technology, broke the monopoly of elite discourse power, for the people in the bottom of the equal dialogue provides a good platform, it is beneficial to enhance the public's voice, and to enhance their sense of participation and supervision, and play an important role in the network supervision by public opinion. [7]

\section{Internet Language Needs to Be Standardized}

Network language is a "double-edged sword", which not only enriches Chinese vocabulary, but also brings some negative effects. Some network language is so obscure that it completely deviates from the basic function of language and makes it difficult to carry out communication activities, which is actually a serious pollution of the Chinese language. For example, "me2" is a shortened version of the English sentence "me, too", which is simple for Internet users but confusing for those who don't study English or use the Internet very little; Another example is "killing people", which means "card game", which is so far from the real meaning that it is hard to understand, even the netizens are not well known. This usage completely violates Grice's conversational "cooperation principle", and also does not conform to the development law of Chinese, so it has little value in social life. Therefore, this kind of network language "as the most important communicative tool in the society" must and "should have certain norms".[12] Admittedly, there is no good or bad language, only refined and vulgar. By its very nature, any language can exist as long as it can be spoken and used.[13] As a social dialect, the network language is equal to the standard language. However, if the Internet language violates the basic function of language, it is not standard. There is no denying that some network 
expressions are really practical and play a role that cannot be replaced by other expressions, making up for the shortage of existing expressions, adding new colors to language expression, and meeting the diverse needs of social language expression. For example, "gelivable" means "to give strength, support, effort, fierce" and so on. Although it is short, it has rich meanings. Like this kind of network language, easy to understand, full of expression, soon become People's daily life language, also enriched into the Chinese vocabulary system.

As is known to all, language always develops in society. [14] social development is the fundamental reason for the emergence of network buzzwords. [15] the prevalence of a certain culture is the reflection of social and cultural psychology and aesthetic taste. However, the development and change of everything always follow a certain rule. Things that violate the objective rule will not last long, and the development of Internet language is no exception. Therefore, the creation and development of network language must serve the public to have vitality, otherwise on the contrary. For example, the use of pictures, punctuation, foreign language, facial expressions, and other expressions such as "rookie (indicating a lower level of application in a certain aspect), starter (represents the forum or post the theme of the forum post person), 886 (bye bye), 5201314 (I love you for life), (-) (mean happy), : (mean not happy), (mean victory)", whether the need for standardization, whether there is vitality, how long it can survive, this remains to be tested.

\section{Concluding Remarks}

In a word, network language is a part of network culture, and also a part of national culture. At present, in the world of "economic globalization" and "cultural diversification", China's soft and hard power is the foundation of the country. In order to improve the comprehensive strength of our country, this aspect of cultural soft power cannot be absent. Therefore, we should use powerful and convenient network media to spread our excellent culture. [16] In the early stage, there was a lack of network language norms, and all kinds of foul language filled the network space, which brought bad effects to people, especially students. However, we should not give up eating for fear of choking, and give correct guidance. At present, netizens pay more and more attention to the society, and their quality is constantly improving. Moreover, they advocate the core socialist values and convey positive energy, which has become the mainstream of netizens' expressions. The country has also gradually strengthened the supervision and regulation of network language, which effectively inhibits the crudeness of network language and is conducive to the cultivation of network civilized language and healthy fashion. Of course, the development of Internet language is in the ascendant, so the national supervision and regulation of it is always on the way.

\section{References}

[1] Yao Zhihua. The "Evolution History" of Chinese Network Language [J]. Lanuage Planning, 2019 (10)

[2] Yu Genyuan. Introduction to Network Language [M]. Beijing: China Ecnomic Publishing House, 2001

[3] Liu Haiyan. The Network Language [M]. Beijing: China Radio \& Television Publishing House, 2002 (1)

[4] Zhang Xuemei, Chen Changlai. The Evolution And Causes of the Internet Buzzword "Anti-Destiny" [J]. Contemporary rhetoric. 2015 (06)

[5] Liu Kaihua, Ziguo Tianran. Meme Propagation of Internet Buzzwords in the Context Of Social Media [J]. Media Observer, 2017 (06)

[6] Tian Yongfang. An Investigation And Analysis of College Students' Use of Internet Buzzwords And Their Attitude: A Case Study of Liberal Arts Students in Business College of Shanxi University $[\mathrm{J}]$. Journal of Jishou University (Social Sciences). 2018 (S2)

[7] Liu Jinming, Ge Yinfeng. A Review of Domestic Research on Network Buzzwords (2008-2018) [J]. Journal of Chongqing University of Sciences And Technology. 2019 (06)

[8] Ye Feisheng, Xu Tongqiang. Linguistic Outline [M]. Peking University Press. 1997

[9] China Internet Network Information Center (CNNIC). The 44th China statistical Report on Internet Development [DB/OL] http://www.cnnic.net.cn/.2019-08-30.

[10] Ministry of Education of the People's Republic of China. Chinese inventory: Top 10 Internet Terms Released in 2019. $[\mathrm{DB} / \mathrm{OL}]$

http://www.moe.gov.cn/jyb_xwfb/gzdt_gzdt/s5987/201912/t2 0191202_410477.html.2019-12-02.

[11] Sheng Yulei. Let Buzzwords Become The Carrier of Positive Energy

[J/OL]. http://media.people.com.cn/nl/2018/0606/c40606-30037730ht ml.2018-06-06.

[12] Zhan Bohui. Some Current Linguistic Phenomena And Linguistic Norms [J]. Jinan Journal (Philosophy \& Social Science Edition), 2001 (04)

[13] Liu Qun. Family Language Planning And Language Relations [J]. Journal of Jiang Xi Normal University (Philosophy \& Social Science Edition), 2017 (06)

[14] Wilhelm von Humboldt. On The Diversity of Human Language Construction And Its Influence on the Mental Development of the Human Species (Chinese Translation) [M]. Beijing: The Commercial Press. 1997

[15] Wu Jianhua, Xu Zhenxing, Ban Sheng. On The New Changes of Public Opinion Supervision in Our Country -- Based on The Perspective of Network Hot Words [J]. Journal of Hunan University of Science \&Technology (Social Science Edition), $2011(05)$

[16] Guo Zhenzhi. International Communication Requires Dexterity [J]. Journal of Jiang Xi Normal University (Philosophy \& Social Science Edition), 2016 (01) 